\title{
AVALIAÇÃO DA MICROESTRUTURA E MICRODUREZA DO AISI 440B NITRETADO A PLASMA*
}

André Kraszczuk ${ }^{1}$ André Paulo Tschiptschin ${ }^{2}$

\section{Resumo}

Esse trabalho avaliou a microestrutura e a microdureza do aço inoxidável martensítico AISI 440B nitretado a plasma em reator de fonte DC pulsada, a $480^{\circ} \mathrm{C}$, por 6 horas e pressão da câmara de 3,3 Torr. Foram utilizadas técnicas de difração de raios-X, microscopia ótica, microscopia eletrônica de varredura (MEV) e microdureza. A camada nitretada apresentou aproximadamente $24 \mu \mathrm{m}$ de espessura, não tendo sido observada a formação de camada branca, constituída exclusivamente por nitretos de ferro ou de cromo. Entretanto, notou-se, na zona de difusão, a presença de nitretos nos contornos de grão, possivelmente, de cromo. $O$ endurecimento superficial do aço AISI 440B, atingiu valores entre 1417 - $1677 \mathrm{HV}_{0,025}$, ao passo que o a matriz metálica do aço temperado apresentou durezas de aproximadamente 54HRc.

Palavras-chave: Nitretação a plasma; Aços inoxidáveis martensíticos; Engenharia de superfície.

\section{MICROSTRUCTURAL AND MICROHARDNESS EVALUATION OF AISI 440B} PLASMA NITRIDED

\begin{abstract}
This study has evaluated the microstructure and microhardness of martensitic stainless steel AISI 440B plasma nitrided at $480^{\circ} \mathrm{C}$ for $6 \mathrm{~h}$ and 3,3 Torr using a DC Pulsed reactor. Techniques such as X-Ray diffraction, optical microscopy, scanning electron microscopy (SEM) and microhardness were used. The resulting microstructure was a nitrided layer of about $24 \mu \mathrm{m}$ thick, white layer was not present, but it was noticed in the diffusion zone the presence of nitrides at the grain boundaries, possibly chrome ones. The magnitude of microhardness improvement on AISI 440B was also measured, the surface hardness after nitriding stayed between 1417 to 1677 $\mathrm{HV}_{0,025}$ whereas the pre-nitrided material hardness was approximately $54 \mathrm{HRc}$.
\end{abstract}

Keywords: Plasma nitriding; Martensitic stainless steel, Surface engineering.

1 Engenheiro de Materiais, Mestrando em Engenharia Metalúrgica e de Materiais, Escola Politécnica da Universidade de São Paulo; São Paulo, SP, Brasil.

2 Professor Livre-Docente, Doutor em Engenharia Metalúrgica e de Materiais, Escola Politécnica da Universidade de São Paulo, São Paulo, SP, Brasil. 


\section{INTRODUÇÃO}

O aço AISI 440B, é um aço inoxidável martensítico, utilizado em motores de combustão interna, na fabricação de anéis de pistão, conforme reportado por PINEDO (2003a). O mesmo salienta que, devido às atuais exigências de redução de consumo de combustível e emissão de $\mathrm{CO}_{2}$, há um forte interesse em processos que permitam aprimorar o desempenho desses materiais quanto ao desgaste, sendo a nitretação um deles. Os anéis fabricados em aço inoxidável martensítico podem ser somente nitretados, ou, conforme mostrado na patente de ARAUJO et al (2009), podem ser recobertos com camadas espessas de $\mathrm{CrN}$ depositadas por processo CAPVD (processo de deposição física de vapor por arco catódico. GAHLIN et al (2001) destacam o uso de revestimentos, principalmente Diamond Like Carbon (DLC) como promissores para o setor automotivo.

LEPICKA e GRADZKA-DAHLKE (2014) destacam outras aplicações tecnológicas dos aços inoxidáveis martensíticos, desde cutelaria e materiais para fabricação de ferramentas para o setor metal mecânico, até o uso em aplicações médicas, tais como implantes e utensílios odontológicos.

A fim de aprimorar as propriedades de superfície, seja para maiores resistências ao desgaste ou para tornar o material mais resistente para uma futura deposição de um filme fino, utiliza-se a nitretação a plasma. PINEDO (2000) destaca que o processo de nitretação a plasma surgiu por volta de 1930, porém desde 1970 vem ganhando destaque e se desenvolvendo fortemente, graças aos avanços em termos de automação e controle.

De forma sucinta, TAKTAK et al (2014) e PINEDO (2000) destacam que a nitretação a plasma é um processo onde ocorre a difusão do nitrogênio atômico no reticulado cristalino do material. A presença desse elemento no reticulado gera pequenos precipitados coerentes e campos de tensões de coerência no material dificultando a movimentação das discordâncias. A microestrutura típica da nitretação pode apresentar ou não a camada de compostos (rica em nitretos de ferro ou de outros elementos formadores de nitretos), porém a camada de difusão, rica em nitrogênio no reticulado cristalino e com precipitados coerentes, sempre estará presente.

Ellingham (1944) apresenta o diagrama de Ellingham onde nota-se que certos elementos apresentam pequena energia livre de formação de nitretos, logo são elementos que tendem a formá-los com maior facilidade que outros. Sendo assim, em materiais cuja composição química apresenta alto teor desses elementos, é favorável a formação da camada branca ou camada de compostos, como forma de reduzir a energia livre do sistema.

PINEDO (2000) discute os diversos nitretos que podem se formar no material, utilizando o diagrama de fases Fe-N. De acordo com o autor, tais nitretos, embora altamente duros, podem reduzir a resistência ao desgaste, visto que a fragilidade típica das fases cerâmicas pode levar a fraturas no material, que, por sua vez, pode levar ao seu lascamento.

ALVES JR et al (2006) discutem uma dificuldade inerente ao processo de nitretação a plasma, o chamado "defeito de borda". O plasma é formado pela ionização dos gases da câmara por meio da aplicação de uma diferença de potencial gerada pela fonte pulsada da nitretação. Devido ao fato de haver distorções no campo elétrico nas regiões das bordas, o plasma tende a envolver as peças, seguindo seus contornos. Uma vez que o plasma circunde a peça, as bordas estarão sob um gradiente de campo elétrico mais intenso, além de receber um maior aporte térmico, aquecendo mais 
nessas regiões e gerando, em consequência, essa heterogeneidade entre a borda e o centro da peça.

TAKTAK et al (2014) destacam outros obstáculos, como o superaquecimento e a formação de arcos, defeitos que podem ser evitados usando o processo de nitretação pulsada, ou seja, utilizando uma fonte que durante um tempo fornece corrente e tensão para a formação do plasma e por um tempo (conhecido como tempo de relaxação) fica inoperante.

Os objetivos desse trabalho são: nitretar a plasma o AISI 440B, caracterizar a microestrutura formada, quanto à presença de nitretos, espessura e dureza da camada nitretada.

Esse trabalho faz parte de um projeto maior que está sendo desenvolvido, que visa comparar a microestrutura, o desempenho mecânico e tribológico do AISI 440B nitretado a plasma, com o mesmo AISI 440B nitretado a plasma e revestido com filmes finos de TiN e DLC.

\section{MATERIAIS E MÉTODOS}

As amostras de aço AISI 440B encontravam-se no formato de pequenos cilindros com $30 \mathrm{~mm}$ de diâmetro e $5 \mathrm{~mm}$ de espessura fabricados por eletroerosão a fio. Os cilindros foram previamente temperados em um forno tubular Lindberg com atmosfera controlada, sendo a temperatura de austenitização de $1040^{\circ} \mathrm{C}$ com tempo de encharque de $1 \mathrm{~h}$, seguida de resfriamento em óleo. Após a têmpera foram feitas medidas de dureza HRc do material base, em durômetro Otto Wolpert Werk. O corpo de prova foi preparado metalograficamente, ou seja, foi lixado (\#220/\#320/\#400/\#600/\#1200) e polido até o pano que continha suspensão abrasiva da ordem de $1 \mu \mathrm{m}$. Depois disso o cilindro foi cortado em quatro pedaços por meio de uma cortadeira de laboratório, sendo assim, o formato final das amostras é de $1 / 4$ de cilindro.

A nitretação a plasma foi desenvolvida em um reator situado no LabPlasma do Departamento de Engenharia Metalúrgica e de Materiais da Escola Politécnica da Universidade de São Paulo, com fonte DC pulsada LIITS PULSA II, de parede fria, ou seja, todo aquecimento da amostra é fruto do bombardeamento de íons. O reator dispõe de controles de vazão (MKS 247D) que regulam a quantidade de até 4 tipos diferentes de gases $\left(\mathrm{H}_{2}, \mathrm{CH}_{4}, \mathrm{Ar}\right.$ e $\left.\mathrm{N}_{2}\right)$, existe também um controlador de pressão Edwards Active Gauge Controller que mede instantaneamente a pressão dentro da câmara, além de um termopar tipo $\mathrm{K}$ que mede a temperatura do porta amostra, Por fim, um controlador CLP na fonte pulsada, permite regular parâmetros, tais como, tempo de duração do pulso, tempo de relaxação, corrente solicitada e tempo de tratamento. O reator também dispõe de uma bomba de vácuo mecânica e outra bomba de vácuo difusora para limpar a câmara antes da nitretação.

Antes de fazer a nitretação a plasma, foi realizado vácuo com a bomba difusora equivalente a $6^{*} 10^{-5}$ Torr, e uma etapa de "sputtering". O objetivo da etapa de sputtering é remover a película passiva formada sobre o AISI 440B através da redução com o gás hidrogênio; além disso, como o reator não dispõe de mecanismo externo de aquecimento é necessário haver o "sputtering" para aquecer a peça até a temperatura de nitretação ou até a temperatura mais próxima possível.

A tabela 1 abaixo ilustra as condições do "sputtering" e da nitretação. 
Tabela 1 - Parâmetros de sputtering e de nitretação a plasma

\begin{tabular}{|c|c|}
\hline Sputtering & \\
\hline Parâmetros & Valor ou Faixa de Valores \\
\hline Tempo (h) & 2 \\
\hline Temperatura Máxima Obtida (으) & 355 \\
\hline Pressão (Torr) & $3-3,5$ \\
\hline Corrente Solicitada (A) & $0,65-0,68$ \\
\hline Corrente Recebida (A) & $0,57-0,61$ \\
\hline Tensão Recebida (V) & $347-362$ \\
\hline Tempo Duração do Pulso $\left(10^{\wedge}-6 \mathrm{~s}\right)$ & 60 \\
\hline Tempo de Relaxação do Pulso (10^-6s) & 60 \\
\hline Fração Volumétrica dos Gases Hidrogênio e Argônio (\%) & $50 / 50$ \\
\hline Vazão dos Gases Hidrogênio e Argônio (sccm) & $40 / 40$ \\
\hline \multicolumn{2}{|l|}{ Nitretação a Plasma } \\
\hline Parâmetros & Valor ou Faixa de Valores \\
\hline Tempo (h) & 6 \\
\hline Temperatura Máxima Obtida (으) & 480 \\
\hline Pressão (Torr) & 3,3 \\
\hline Corrente Solicitada (A) & 0,8 \\
\hline Corrente Recebida (A) & 0,78 \\
\hline Tensão Recebida (V) & $478-480$ \\
\hline Tempo Duração do Pulso $\left(10^{\wedge}-6 \mathrm{~s}\right)$ & 60 \\
\hline Tempo de Relaxação do Pulso (10^-6s) & 60 \\
\hline Fração Volumétrica dos Gases Nitrogênio e Hidrogênio (\%) & $75 / 25$ \\
\hline Vazão dos Gases Nitrogênio e Hidrogênio (sccm) & $120 / 40$ \\
\hline
\end{tabular}

Os difratogramas para determinação de fases precipitadas foram feitos em difratômetro Philips XPert do Laboratório de Caracterização Tecnológica do Departamento de Engenharia de Minas e Petróleo da Escola Politécnica da Universidade de São Paulo. Foi utilizada radiação $\operatorname{CuK} \alpha(\lambda=0,154060 \mathrm{~nm})$, corrente de $40 \mathrm{~mA}$ e tensão de $40 \mathrm{kV}$ e foi considerado como intervalo de varredura os ângulos entre $20^{\circ}-120^{\circ}$, considerando um passo de $0,02^{\circ} / \mathrm{min}$, o que totalizou um tempo de 200 minutos.

A microscopia ótica foi realizada em um microscópio OLYMPUS BX60M que possui interface com o software analisador de imagens TSView-7. A microscopia eletrônica de varredura foi feita em um Philips XL30 TMP, utilizando-se uma tensão de 20kV em um filamento de W, bem como o detector BSE. Em ambas as técnicas o material observado foi atacado com o reagente Nital $2 \%$ por 2 minutos.

Medidas de microdureza foram realizadas por meio de um microdurômetro HMV 2 Shimadzu situado sobre uma mesa antivibratória TS-300/LT, para as microdurezas superficiais foram utilizadas a carga de $25 \mathrm{gf}$, as indentações foram coletadas a $3 \mathrm{~mm}$ de cada borda da superfície, lembrando que a superfície é representada por $1 / 4$ de círculo.

\section{RESULTADOS E DISCUSSÃO}

O AISI 440B utilizado apresentou a seguinte composição química média, obtida por meio de espectrômetro por dispersão de energia (EDS), acoplado ao microscópio eletrônico de varredura e mostrada na tabela 2 abaixo. 
Tabela 2 - Composição Química Média do AISI 440B

\begin{tabular}{llllll}
\hline & $\mathrm{Si}$ & $\mathrm{Mo}$ & $\mathrm{Cr}$ & $\mathrm{Mn}$ & $\mathrm{Fe}$ \\
\hline Média & 0,69 & 0,93 & 15,95 & 0,61 & 81,82 \\
\hline Desvio & 0,2 & 0,36 & 1,99 & 0,16 & 2,22 \\
\hline
\end{tabular}

A microestrutura do material temperado é mostrada na figura 1.

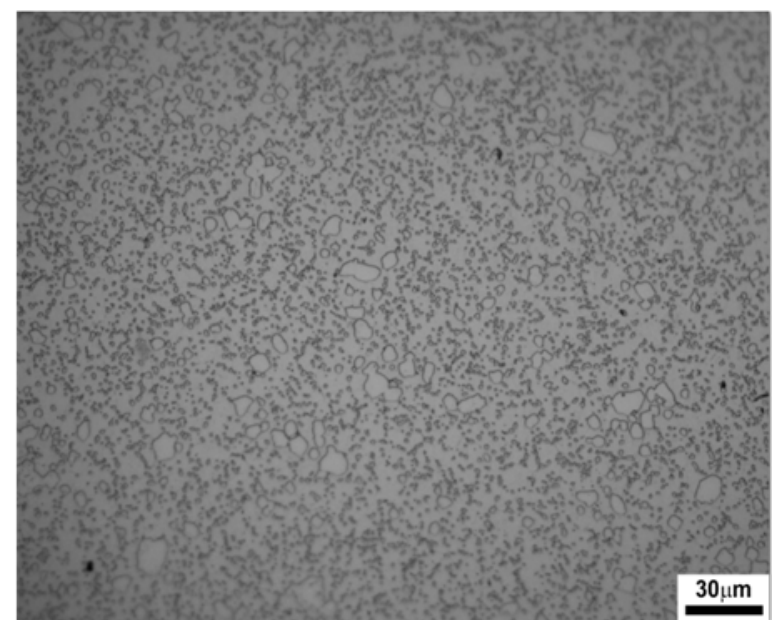

Figura 1 - Microestrutura do AISI 440B temperado em óleo a $1040^{\circ} \mathrm{C}$. Aumento: 500x. Ataque: Villela.

Notou-se a presença de carbonetos secundários, ricos em cromo, do tipo $\mathrm{M}_{23} \mathrm{C}_{6}$, não dissolvidos na matriz martensítica, a microestrutura obtida condiz com o trabalho de DE CARVALHO e MAGNABOSCO (2005) que efetuaram tratamentos térmicos de têmpera e revenimento em um aço inoxidável martensítico (AISI 420), provavelmente a quantidade de carbonetos que esses autores obtiveram é menor que a quantidade obtida com o AISI 440B, devido a diferenças em termos de composição química, com menores teores de cromo e carbono.

A dureza do material temperado é mostrada na tabela 3 abaixo.

\begin{tabular}{cc} 
Tabela 3 - Durezas do AISI 440B temperado \\
\hline Medidas & Durezas (HRc) \\
\hline 1 & 51,0 \\
2 & 53,0 \\
3 & 56,0 \\
4 & 56,0 \\
5 & 52,0 \\
6 & 54,0 \\
7 & 55,0 \\
8 & 56,0 \\
Média & 54,1 \\
Desvio Padrão & 2,0 \\
\hline
\end{tabular}

Foi possível notar que a dureza obtida na condição temperada se encontra dentro da faixa de valores informada por ASM INTERNATIONAL (1991) que é entre 53-59 HRc O difratograma do material nitretado é ilustrado na figura 2 abaixo. 

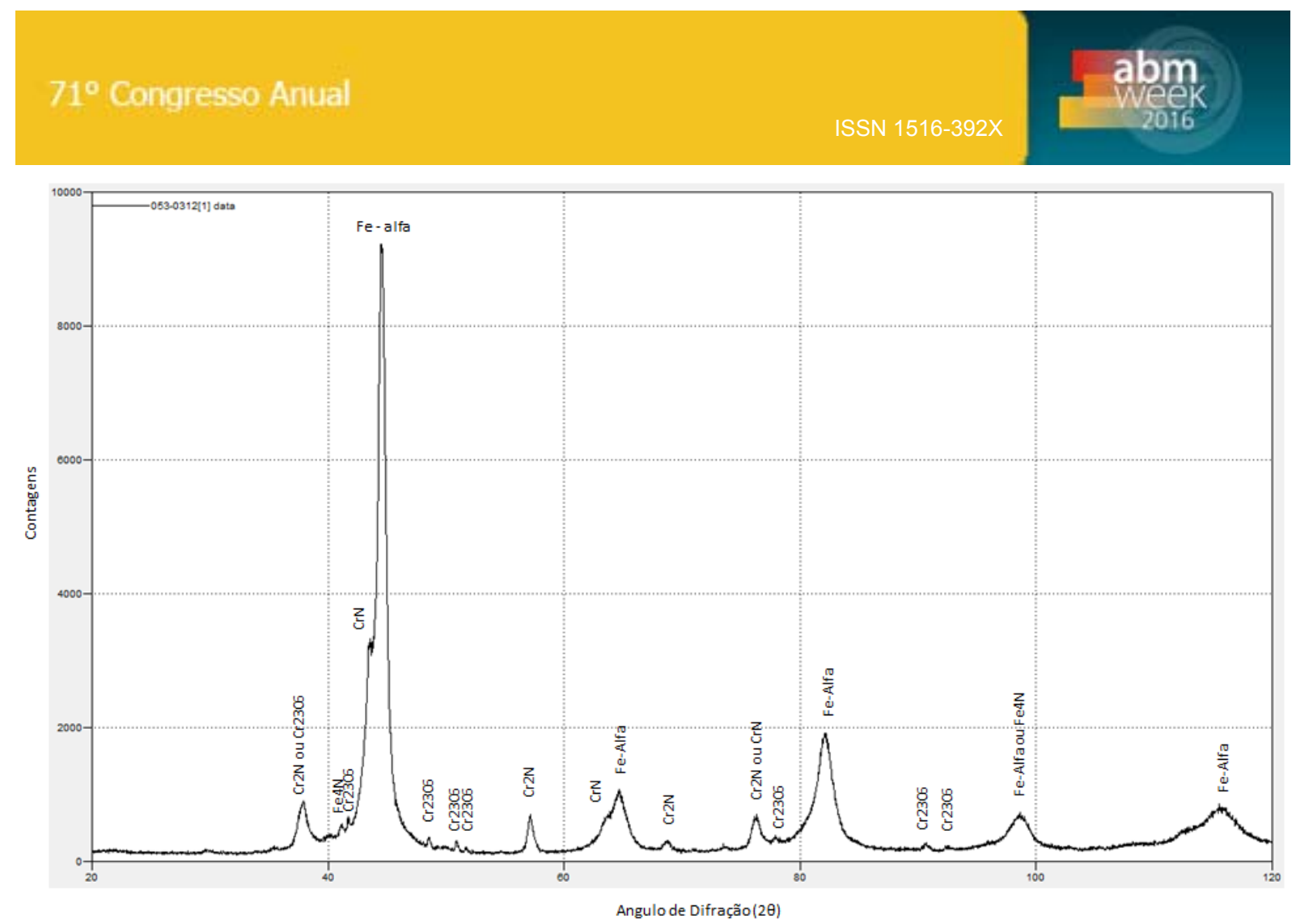

Figura 2 - Difratograma do AISI 440B nitretado conforme condições preestabelecidas.

Segundo o difratograma, é possível identificar basicamente a presença de picos de fase CCC, identificada como martensita (revenida na nitretação), enriquecida em nitrogênio, e a presença de nitretos de cromo, tanto os nitretos $\mathrm{CrN}$ quanto o $\mathrm{Cr}_{2} \mathrm{~N}$. Muito embora o cromo seja um elemento altamente formador de carboneto, especialmente em altas quantidades, conforme afirmado por PINEDO (2000); ainda assim foi possível identificar o nitreto de ferro $\left(\mathrm{Fe}_{4} \mathrm{~N}\right)$ conhecido também como y'. Por fim, comprovou-se a existência dos carbonetos secundários não dissolvidos na têmpera e consequentemente não dissolvidos na nitretação, precipitados em temperaturas bem inferiores à temperatura de austenitização.

PINEDO (2003b) estudou a nitretação de aço inoxidável martensítico AISI 420 e obteve os mesmos nitretos identificados acima, porém obteve também o nitreto de ferro do tipo $\mathrm{Fe}_{2-3} \mathrm{~N}(\varepsilon)$, além de ter constatado a formação de camada branca. Provavelmente isso ocorreu porque trabalhou com temperaturas mais elevadas $\left(560^{\circ} \mathrm{C}\right.$ por $\left.4 \mathrm{~h}\right)$ e liga com menor teor de cromo. O trabalho de DALIBON et al (2013) sugere que as nitretações de aço inoxidável martensíticos em temperaturas baixas, da ordem de $390^{\circ} \mathrm{C}$, são incapazes de formar nitretos de cromo, porém ainda é possível a formação de nitreto de ferro $\left(\mathrm{Fe}_{3} \mathrm{~N}\right.$ e $\left.\mathrm{Fe}_{4} \mathrm{~N}\right)$, o que induz que o nitreto de ferro do AISI 440B formou-se primeiro, seguido da formação dos nitretos de cromo. TAKTAK et al (2014) em seus estudos com AISI 440C também identificou os mesmos nitretos e o grande pico de Fe-alfa apontados no difratograma do AISI 440B, porém apresentou também a fase $\varepsilon$, como observado por PINEDO (2003b).Talvez a não formação do nitreto de ferro $\mathrm{Fe}_{2-3} \mathrm{~N}$ no AISI 440B nitretado nesse trabalho seja devido ao não atingimento da fração mássica de $\mathrm{N}$ necessária para formar o reticulado hexagonal compacto desse nitreto, conforme sugerido pelo diagrama $\mathrm{Fe}-\mathrm{N}$ apresentado por PINEDO (2000). O não atingimento de uma grande fração mássica de $\mathrm{N}$ pode ser correlacionada com a espessura da camada, se tivesse ocorrido uma maior difusão de $\mathrm{N}$ provavelmente se encontraria uma camada mais espessa e a fase $\varepsilon$. 
A microscopia ótica da camada nitretada é apresentada na figura 3 abaixo

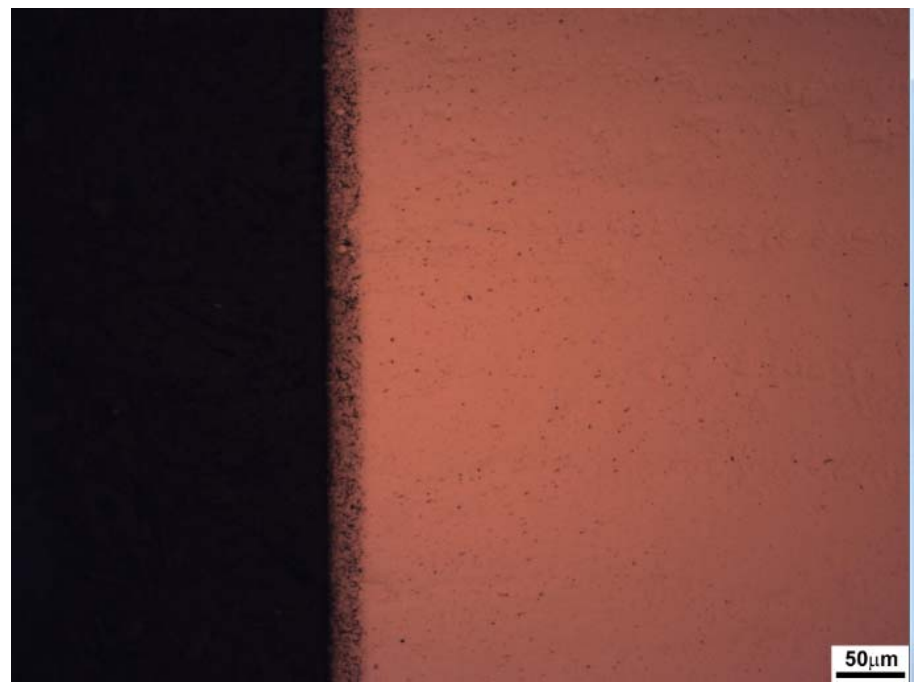

Figura 3 - Microscopia ótica do AISI 440B nitretado conforme condições preestabelecidas. Aumento: 200x. Ataque: Nital $2 \%$ por 2 minutos.

Notou-se que a camada se apresenta de forma contínua, com espessura contínua ao longo da superfície nitretada, a microscopia em aumentos de $500 x$ ou superior permitem visualizar os carbonetos não dissolvidos. Segundo PINEDO (2003b) o ataque com Nital revela somente a camada nitretada (camada branca + zona de difusão), que por sua vez, tem esse nome graças ao aspecto branco encontrado quando atacada com Nital. As medidas de espessura da camada nitretada obtidas por meio de microscopia ótica são apresentadas na tabela 4 abaixo.

\begin{tabular}{cc} 
Tabela 4 - Medidas de Espessura da Camada Nitretada obtida via microscopia ótica \\
\hline Medições & Espessura da Camada (mícrons) \\
\hline 1 & 24,35 \\
\hline 2 & 23,65 \\
\hline 3 & 21,57 \\
\hline 4 & 24,70 \\
\hline 5 & 20,87 \\
\hline 6 & 23,30 \\
\hline 7 & 22,61 \\
\hline 8 & 20,87 \\
\hline 9 & 24,00 \\
\hline 10 & 24,00 \\
\hline Média & 22,99 \\
\hline Desvio Padrão & 1,43 \\
\hline
\end{tabular}

Notou-se que embora a temperatura seja elevada, a espessura da camada não pareceu tão espessa, comparando-se resultados de nitretações de AISI 420 em temperaturas maiores, como descritos por PINEDO (2000) e PINEDO (2003b), notase que a $480^{\circ} \mathrm{C}$ por $4 \mathrm{~h}$ em atmosfera de $75 \%$ nitrogênio o AISI 420 apresentou uma camada de aproximadamente $50 \mu \mathrm{m}$, ou seja, o dobro da camada obtida com a mesma temperatura, mesma atmosfera adotada nesse estudo e com um tempo inferior ao desse estudo. Isso induz acreditar que a composição química do AISI 440B 
influenciou bastante na difusão do nitrogênio que ficou dificultada com a presença de maiores teores de $\mathrm{Cr}$ e $\mathrm{C}$.

Como o carbono também ocupa os sítios intersticiais da microestrutura do material, talvez possa haver uma concorrência entre $\mathrm{C}$ e $\mathrm{N}$ pela ocupação desses sítios, o que, em teoria, dificultaria a difusão do nitrogênio no AISI 440B (alto C) e causaria uma camada pequena frente à elevada temperatura e tempo empregados.

LEPICKA e GRADZKA - DAHLKE (2014) bem como TAKTAK et al (2014) utilizaram em suas nitretações maiores teores de hidrogênio na atmosfera, provavelmente porque como o aço inoxidável martensítico apresenta elevado teor de $\mathrm{Cr}$, especialmente o AISI 440B, é provável que o material passive muito rapidamente e segundo esses autores, essa passivação dificulta a difusão do nitrogênio e consequentemente a espessura da camada. PINEDO (2000) menciona que, uma vez formado, o $\mathrm{CrN}$ tende a dificultar a difusão do $\mathrm{N}$ rumo ao substrato, visto que o $\mathrm{N}$ estaria combinado com $\circ \mathrm{Cr}$, portanto não estaria mais livre para difundir na microestrutura. O alto teor de $\mathrm{Cr}$, elemento formador de nitreto, no AISI 440B pode ter dificultado a difusão e espessamento da camada, justificando assim os valores baixos de espessura da camada encontrados.

TAKTAK et al (2014) obtiveram resultados que contradizem a hipótese que o carbono dificulta a difusão, mas reforçam a hipótese que precisa de maiores teores de $\mathrm{H}_{2}$ para evitar a passivação, uma vez que com o AISI 440C, semelhante ao AISI 440B, ele foi capaz de obter camadas bem maiores, tanto para o processo pulsado quanto 0 processo convencional, com atmosferas de $75 \% \mathrm{H}_{2}$ e de $50 \% \mathrm{H}_{2}$. Se o trabalho de TAKTAK et al (2014) permite induzir que tenha sido baixo o teor de $\mathrm{H}_{2}$ praticado na nitretação desse trabalho, o que ocasionou a baixa espessura de camada, PINEDO (2003a) obteve resultados que contradiriam isso, pois ao nitretar AISI $440 \mathrm{~B}$ a $520^{\circ} \mathrm{C}$ por $8 \mathrm{~h}$ em atmosfera com $75 \% \mathrm{~N}_{2}$ (mesmo teor de $\mathrm{H}_{2}$ usado nesse trabalho) foi capaz de obter espessura de camada de $105 \mu \mathrm{m}$, ou seja, mesmo com bastante $\mathrm{C}$, bastante $\mathrm{Cr}$ e pouco $\mathrm{H}_{2}$ ele obteve uma espessura elevada. Talvez a diferença entre os resultados obtidos seja ocasionada por um potencial de nitrogênio no reator menor ou uma interação mais complexa envolvendo tempo, temperatura, atmosfera e até as características dos reatores usados.

A Figura 4 mostra a imagem obtida em microscópio eletrônico de varredura. Observam-se carbonetos de cromo não dissolvidos, é possível notar também a presença de pontos pretos, o que foi atribuído à formação de nitretos de cromo no contorno de grão conforme previamente detectado na difração de raios-X. TAKTAK et al (2014) também apresentaram carbonetos não dissolvidos em seus trabalhos com AISI 440C, o que demonstra que é natural a presença dos mesmos. 

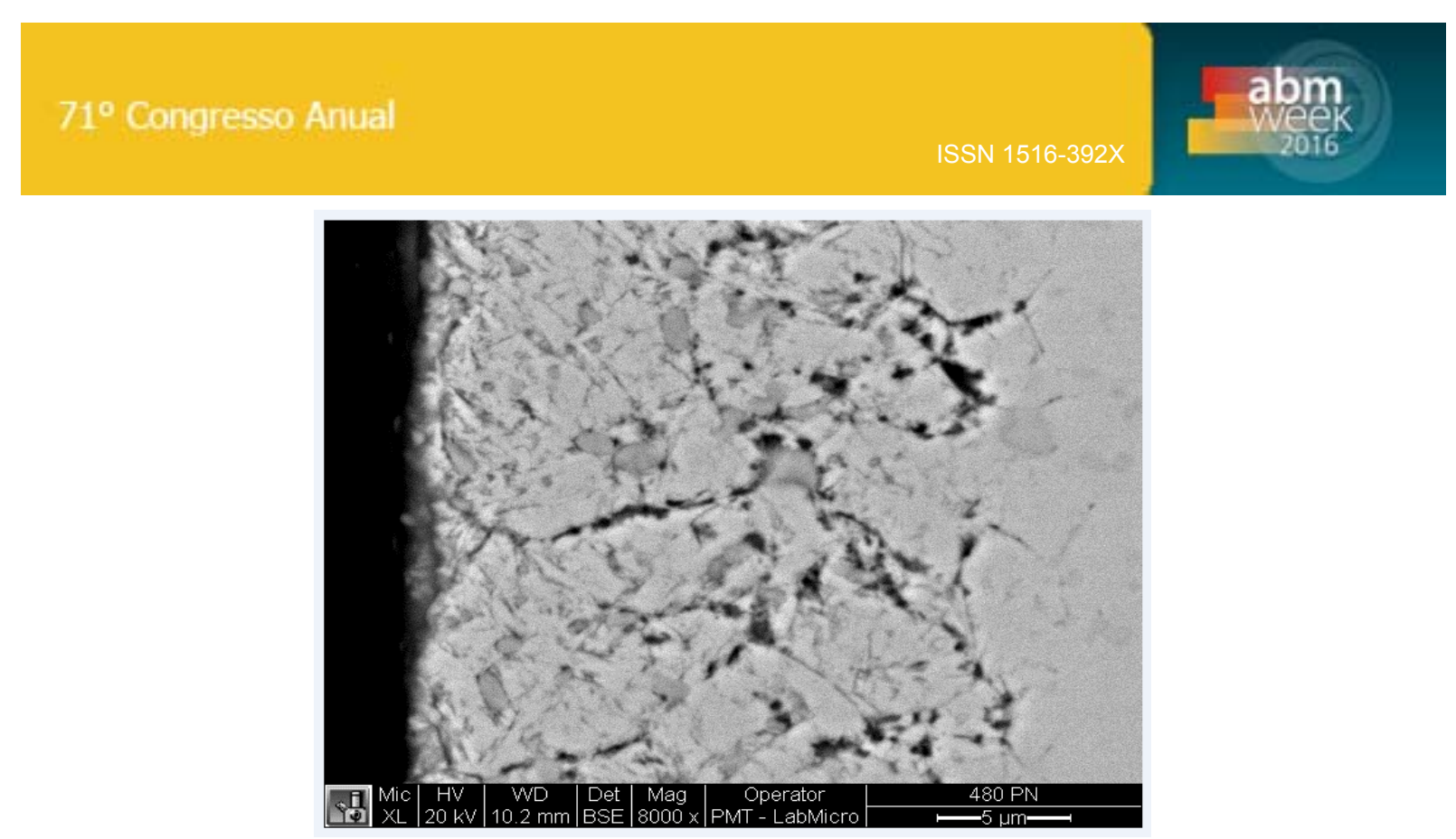

Figura 4 - Microscopia Eletrônica de Varredura do AISI 440B nitretado conforme condições preestabelecidas. Aumento: 8000x. Ataque: Nital 2\% por 2 minutos.

Por fim, as medidas de microdureza superficial são apresentadas na tabela 5 abaixo.

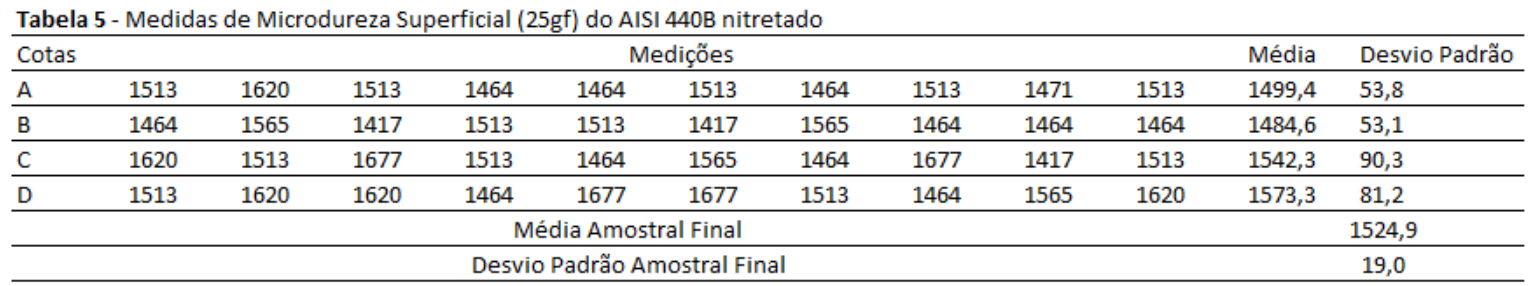

As cotas $A, B, C$ referem-se às três bordas da amostra em formato de $1 / 4$ de cilindro (lembrando que as medidas foram coletas a $3 \mathrm{~mm}$ da borda), e o termo $\mathrm{D}$, refere-se ao centro dessa superfície. Pode-se notar que as durezas nas quatro cotas são semelhantes, sendo os desvios provavelmente explicáveis pela imprecisão de leitura que o próprio método fornece, bem como uma variabilidade intrínseca natural em qualquer microestrutura. Mesmo obtendo-se uma pequena camada nitretada, por meio do uso de cargas baixas ( $25 \mathrm{gf}$ ), foi possível constatar que ela tem um valor de dureza geral equivalente a $1524,9 \mathrm{HV}$ com 25 gf de carga, um valor bem elevado. Deve-se lembrar também que a baixa carga aumenta a probabilidade dessa dureza representar a dureza somente da camada nitretada.

As medidas de microdureza da maioria dos autores refere-se a medidas de dureza superficial na seção transversal da amostra, sabe-se que ao medir a dureza superficial pela secção transversal implica em coletar dados ligeiramente $(0-10 \mu m)$ abaixo da superfície do material, pois senão não é possível ler a indentação fabricada, essa ligeira diferença, aliada a diferenças nas cargas usadas, pode explicar porque as microdurezas obtidas pelos autores citados abaixo são diferentes dos valores mostrados na tabela 5 . Deve-se lembrar que os valores mostrados na tabela 5 referem-se somente a medições de dureza na superfície longitudinal do material e não medições de dureza na superfície transversal da amostra. Mesmo assim, pretende-se refletir sobre a microdureza informada na tabela 5 , analisando-se resultados de outros autores.

PINEDO (2003b) apresentou medidas de microdureza superficial para seus tratamentos a $480^{\circ}-560^{\circ} \mathrm{C}$ para AISI 420 , segundo seus resultados, a microdureza 
superficial situa-se entre 1500 e $1600 \mathrm{HV}_{0,025}$, esse valor elevado se deve a formação da camada branca, o que explicaria o fato de um aço (AISI 420) com menos elementos de liga (carbono e cromo) que o AISI 440B apresentar maior dureza que ele. PINEDO (2003a) em seus estudos com AISI 440B obteve durezas da ordem de 1100-1200 $\mathrm{HV}_{0,1}$, o que provavelmente representam valores análogos aos mostrados na tabela 5 , se tivesse sido usado uma carga menor e as medições referissem a seção longitudinal.

TAKTAK et al (2014) apresentou durezas superficiais para o AISI 440C, suas medições foram inferiores às do AISI 440B da tabela 5 , novamente essa diferença deve ser devido ao uso de cargas diferentes e de métodos diferentes (medições na superfície da seção longitudinal x medições na superfície da seção transversal).

\section{CONCLUSÃO}

Com base no trabalho efetuado concluiu-se que:

a) É possível nitretar o AISI $440 \mathrm{~B}$ a $480^{\circ} \mathrm{C}$ por $6 \mathrm{~h}$ e com pressões da ordem de 3,3 Torr;

b) A microestrutura formada apresenta carbonetos secundários do tipo $\mathrm{M}_{23} \mathrm{C}_{6}$ ricos em $\mathrm{Cr}$, esses carbonetos são oriundos da incapacidade de dissolução dos mesmos na têmpera, além de nitretos $\mathrm{CrN}$; $\mathrm{Cr}_{2} \mathrm{~N}$ e $\mathrm{Fe}_{4} \mathrm{~N}$.

c) O DRX sugere que os nitretos encontrados nos contornos de grão vistos na figura 4 sejam ou nitretos de cromo ou nitreto de ferro;

d) Não foi identificada a formação de camada branca ao contrário de alguns trabalhos aqui analisados na seção "Resultados \& Discussões", isso provavelmente se deve ao fato de que esses autores usaram temperaturas superiores a $480^{\circ} \mathrm{C}$ e até tempos maiores que $6 \mathrm{~h}$;

e) A camada nitretada apresenta aproximadamente $24 \mu \mathrm{m}$ de espessura, espessura bem inferior aos trabalhos da literatura e que ainda constituem uma oportunidade de estudo para entender o que de fato causou esse fenômeno;

f) As durezas superficiais encontram-se entre 1417-1677 $\mathrm{HV}_{0,025}$, o que parece ser superior aos valores publicados pelos autores analisados nesse artigo, mas na verdade a inferioridade dos valores desses autores provavelmente se deve ao fato deles terem obtido esses dados de forma diferente da forma apresentada nesse artigo.

\section{Agradecimentos}

O autor agradece a CAPES pela bolsa do tipo PROEX fornecida e agradece também a Universidade de São Paulo, seus colegas de trabalho pela oportunidade de realização do trabalho, pelas valiosas sugestões e pelo incentivo.

\section{REFERÊNCIAS}

1 PINEDO, Carlos Eduardo. The use of selective plasma nitriding on piston rings for performance improvement. Materials \& Design, v.24, 131-135, 2003a.

2 ARAUJO, Juliano Avelar. MARQUES, Giseba Abias, SARABANDA, Jose Valentim Lima, BANFIELD, Robert Richard. Piston Ring with Chromium Nitride Coating for Internal Combustion Engines. Patente No US20090278320, 2009.

3 GAHLIN, Rickard. LARSSON, Mats. HEDENQVIST, Per. Me-C:H Coatings in Motor Vehicles. Wear, v249, 302-309, 2001. 
4 LEPICKA, Magdalena. GRADZKA-DAHLKE, Malgorzata. Effect of Plasma Nitriding Process Conditions on Corrosive Resistance of AISI 440B Martensitic Stainless Steel.Acta Mechanica et Automatica, v8, n³, 156-159,2014.

5 PINEDO, Carlos Eduardo. Estudo Morfológico e Cinético da Nitretação Por Plasma Pulsado do Aço Inoxidável Martensítico AISI 420. Tese (Doutorado) apresentada ao IPEN - Instituto de Pesquisas Energéticas e Nucleares, São Paulo, SP,2000,203p. TAKTAK, Sukru. GUNES, Ibrahim. ULKER, Sukru. Effect of pulse plasma nitriding on tribological properties of AISI 52100 and AISI 440C Steels. Int.J. Surface Science and Engineering, v8, n1, 39-56, 2014.

7 ELINGHAN, H.J.T. Reducibility of Oxides and Sulphides in Metallurgical Processes. Journal of the Society of Chemical Industry, 126-133, Maio 1944.

8 ALVES JR, C. DE ARAUJO, F.O. RIBEIRO, KJB. DA COSTA, J.A.P. SOUSA, R.R.M. DE SOUSA, R.S.Use of cathodic cage in plasma nitriding. Surface and Coating Technology, v201, 2450-2454, 2006.

9 DE CARVALHO, RENNÊ ROJAIS; MAGNABOSCO, RODRIGO. Previsão da Vida em Fadiga de Aço Inoxidável Martensítico UNS S42000. Parte I: Material Temperado e Revenido a $500^{\circ} \mathrm{C}$. Relatório Final de Iniciação Científica do Depto de Enga Mecanica FEI - Trabalho apresentado ao $12^{\circ}$ Simpósio Internacional de Iniciação Científica da USP. SIICUSP, 25-26 de novembro de 2004, 51p.Endereço Eletrônico: http://fei.edu.br/ rodrmagn/PROJETOS IC/2005/RRC2004.pdf. Acessado em 4/3/2016

10 ASM INTERNATIONAL. ASM Handbook - Vol 4 - Heat Treating. ASM International, Materials Park, Ohio, 1991, 1012p.

11 PINEDO, Carlos Eduardo. Tratamento Térmico e Superficial do Aço Inoxidável Martensítico AISI 420 destinados a molde para injeção de polímeros - Parte II Tratamento Superficial. Trabalho apresentado ao $2^{\circ}$ Encontro da Cadeia de Ferramentas, Moldes e Matrizes, ABM, 21-23 de Setembro de 2003b, São Paulo, SP.

12 DALIBON, Eugenia L. CHARADIA, Raul. CABO, Amado. TRAVA-AIROLDI, Vladimir. BRÜHL, Sonia P. Evaluation of the mechanical behaviour of DLC filmo $n$ plasma nitrided AISI 420 with different surface finishing. Surface and Coating Technology, v235, 735-740, 2013. 